BMJ Paediatrics Open

\title{
COVID-19 in children in Odisha state, India: a retrospective review
}

Girish Chandra Dash, ${ }^{1}$ Subhra Subhadra, ${ }^{1}$ Jyotirmayee Turuk, ${ }^{2}$ Debaprasad Parai, ${ }^{1}$ Usha Kiran Rout, ${ }^{1}$ Sonalika Rath, ${ }^{2}$ Jyotsnamayee Sabat, ${ }^{2}$ Rashmi Ranjan Nanda, ${ }^{1}$ Hari Ram Choudhary, ${ }^{1}$ Sanghamitra Pati, ${ }^{1}$ Debdutta Bhattacharya ${ }^{1}{ }^{1}$

To cite: Dash GC, Subhadra S, Turuk J, et al. COVID-19 in children in Odisha state, India: a retrospective review. BMJ Paediatrics Open 2021;5:e001284. doi:10.1136/ bmjpo-2021-001284

GCD and SS contributed equally.

Received 3 September 2021 Accepted 25 October 2021
Check for updates

(C) Author(s) (or their employer(s)) 2021. Re-use permitted under CC BY-NC. No commercial re-use. See rights and permissions. Published by BMJ.

${ }^{1}$ Department of Microbiology, Regional Medical Research Centre Bhubaneswar, Bhubaneswar, Orissa, India ${ }^{2}$ VRDL, Regional Medical Research Centre Bhubaneswar, Bhubaneswar, Orissa, India

Correspondence to Dr Debdutta Bhattacharya; drdebdutta.bhattacharya@ yahoo.co.in

Dr Sanghamitra Pati; drsanghamitra12@gmail.com

\section{ABSTRACT}

We retrospectively analysed the swab samples tested for COVID-19 from 7 March 2020 to 17 August 2021 at the Indian Council of Medical Research-Regional Medical Research Centre, Bhubaneswar, Odisha. 553763 nasopharyngeal swabs were collected from individuals suspected with COVID-19 in Odisha state. 75190 (13.6\%) samples were positive by reverse transcription-PCR. There were $5988(8 \%)$ cases in children and young people under 18 years old. Odisha reported 996153 COVID-19 cases which resulted in 6985 deaths in adults and 36 in children and young people under 18 years old.

COVID-19 affects children of all ages, but they rarely develop any severe or critical illness. ${ }^{1}$ India has been hit by two major waves of the COVID-19 pandemic, with peaks in September 2020 and May 2021. ${ }^{2}$ More than $2 \%$ of the 44.5 million population of Odisha were diagnosed with COVID-19 infection during this period.

In this study, we retrospectively analysed the swab samples tested from 7 March 2020 to 17 August 2021 at the Indian Council of Medical Research (ICMR)-Regional Medical Research Centre (RMRC), Bhubaneswar, Odisha. RMRC, Bhubaneswar is the first laboratory to start testing COVID-19 samples in the state and has expanded to a network of 64 laboratories during the COVID-19 pandemic. All samples collected according to the ICMR guidelines were included in the study, except

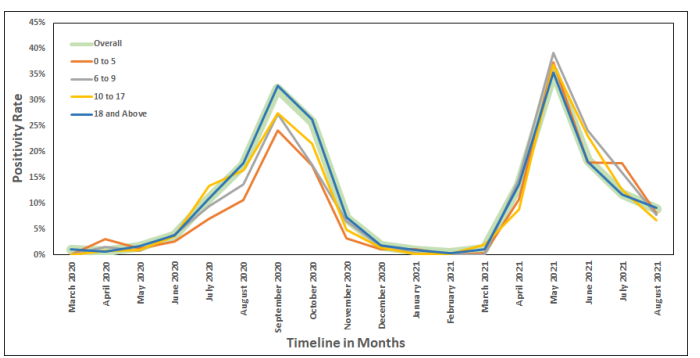

Figure 1 Positivity rate during various months in various age groups. (I have the permission to use the image as it is created by myself and approved by all coauthors). samples which were invalid or inconclusive after testing.

A total of 553763 reverse transcription (RT)-PCR-tested results were included in the analysis. Among the samples tested, 75190 $(13.6 \%)$ were found positive by RT-PCR test according to the guidelines issued by the ICMR, Ministry of Health and Family Welfare, Government of India. Among the positive cases, 69202 (92\%) were from individuals aged $\geq 18$ years and $5988(8 \%)$ cases belonged to aged $0-17$ years. The positivity rate among those aged $\geq 18$ years $(13.8 \%)$ was relatively higher than those aged $0-17$ years $(11.6 \%)$ and comparable with the overall positivity (figure 1). Among children, the positivity rate was highest in the 6-9 years age group $(12.96 \%)$ and lowest among the $0-5$ years age group $(9.07 \%)$. The median age (Q1-Q3) of childhood cases was 13 years (8-15 years) and the median age $(\mathrm{Q} 1-\mathrm{Q} 3)$ of cases above 18 years was 35 years (26-48 years) (figure 2 ).

Our findings demonstrated that the positivity rate among children was less than the adults during the last two COVID-19 waves. The case fatality rates in Odisha state in the $0-17$ years age group were $0.05 \%$ and $0.03 \%$, respectively, in the first and second waves, which were much lower than the overall case fatality $(0.75 \%)$. In 2021, 4, 11 and 8 children succumbed to COVID-19 in the age groups 0-6, 7-14 and 15-18 years, respectively, whereas the number of deaths was 3, 6 and 4 in the same age groups in 2020 . Based on serosurveillance reports conducted by the ICMR in June 2021, COVID-19 infection in children above 10 years of age occurs in a similar frequency to that of adults. The seroprevalence in the 10-17 years age group and $\geq 18$ years increased from $27.8 \%$ to $61.8 \%$ and from $25.8 \%$ to $69.69 \%$, respectively, in the third (December 2020-January 2021) and fourth (June-July 2021) serosurvey. ${ }^{3}$ None of the children had any comorbidities as per the data collected during sample collection. Fear of mutations causing more 


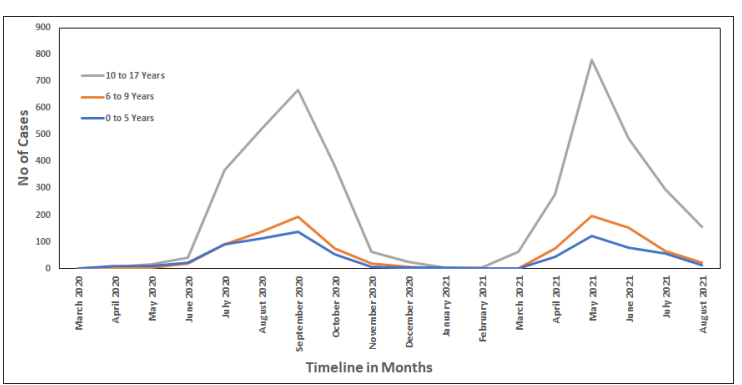

Figure 2 Epidemic curve of COVID-19 in children by age group. (I have the permission to use the image as it is created by myself and approved by all coauthors).

severe cases in children has no solid scientific evidence to date. The most successful strategy to return children to schools is to increase vaccine eligibility for children and adolescents while addressing vaccine hesitancy. Immunisation of school teachers and staff is being prioritised to prevent occupational transmission, and there is a gradual emergence of evidence of vaccine effectiveness in adolescents. ${ }^{4}$ Even without vaccination, due to the high prevalence of seropositivity, children might incur natural immunity in preventing future infection or complications of COVID-19. ${ }^{5}$ An expanding vaccine eligibility for children and adolescents while addressing hesitancy is the most effective strategy in returning children to schools and colleges. ${ }^{6}$ The study highlights that presently there is no such concrete evidence to show that children are or would be affected more than adults in the upcoming waves. To address any future upsurge, a collaborative effort from the private and public sectors is the need of the hour.

\section{Twitter Debdutta Bhattacharya @drdebduttab}

Acknowledgements The authors gratefully acknowledge all the healthcare workers for their tireless dedication at each level to fight COVID-19 and for voluntarily participating in this cohort study.
Contributors DB and SP designed the study. GCD, SS, JT, DP, SR, JS, UKR and RRN were involved in testing and analysis of data. GCD, SS, HRC and DB were responsible for data analysis and valuable inputs. SP, DB, GCD and SS wrote the manuscript. All authors have read and approved the final manuscript.

Funding The Indian Council of Medical Research, New Delhi and the Department of Health and Family Welfare, Government of Odisha provided financial support to the study.

Competing interests None declared.

Patient and public involvement Patients and/or the public were not involved in the design, or conduct, or reporting, or dissemination plans of this research.

Patient consent for publication Not required.

Provenance and peer review Not commissioned; externally peer reviewed.

Open access This is an open access article distributed in accordance with the Creative Commons Attribution Non Commercial (CC BY-NC 4.0) license, which permits others to distribute, remix, adapt, build upon this work non-commercially, and license their derivative works on different terms, provided the original work is properly cited, appropriate credit is given, any changes made indicated, and the use is non-commercial. See: http://creativecommons.org/licenses/by-nc/4.0/.

\section{ORCID iD}

Debdutta Bhattacharya http://orcid.org/0000-0001-5199-5288

\section{REFERENCES}

1 Ladhani SN, Amin-Chowdhury Z, Davies HG, et al. COVID-19 in children: analysis of the first pandemic peak in England. Arch Dis Child 2020;105:1180-5

2 Ministry of health and family welfare, government of India (COVID-19) Dashboard. Available: https://www.mohfw.gov.in/ [Accessed 24 Aug 2021].

3 Murhekar MV, Bhatnagar T, Thangaraj JWV. Prevalence of Igg Antibodies Against SARS-CoV-2 Among the General Population and Healthcare Workers in India, June-July 2021 [Internet]. Report No.: ID 3899801. Rochester, NY: Social Science Research Network, 2021. https://papers.ssrn.com/abstract=3899801

4 Irfan O, Li J, Tang K, et al. Risk of infection and transmission of SARSCoV-2 among children and adolescents in households, communities and educational settings: a systematic review and meta-analysis. $J$ Glob Health 2021;11:05013.

5 Dowell AC, Butler MS, Jinks E, et al. Children develop strong and sustained cross-reactive immune responses against spike protein following SARS-CoV-2 infection. Medrxiv 2021.

6 Kamidani S, Rostad CA, Anderson EJ. COVID-19 vaccine development: a pediatric perspective. Curr Opin Pediatr 2021;33:144-51. 